\title{
CCL5/RANTES IS A KEY CHEMOATTRACTANT RELEASED BY DEGENERATIVE INTERVERTEBRAL DISCS IN ORGAN CULTURE
}

\author{
G. Pattappa ${ }^{1}$, M. Peroglio' ${ }^{1}$, D. Sakai ${ }^{2}$, J. Mochida$^{2}$, L.M. Benneker ${ }^{3}$, M. Alini ${ }^{1}$ and S. Grad ${ }^{1, *}$ \\ ${ }^{1}$ AO Research Institute, Davos, Switzerland \\ ${ }^{2}$ Department of Orthopaedic Surgery, Surgical Science, Tokai University School of Medicine, Isehara, \\ Kanagawa, Japan \\ ${ }^{3}$ Department of Orthopaedic Surgery, University of Bern, Bern, Switzerland
}

\begin{abstract}
Release of chemotactic factors in response to tissue damage has been described for different musculoskeletal tissues, including the intervertebral disc (IVD). This study investigated the chemoattractants that are released by induced degenerative IVDs and may be involved in recruiting mesenchymal stem cells (MSCs). Bovine caudal discs were cultured within a bioreactor and loaded under conditions that mimicked physiological or degenerative settings. Between days 4-6, medium was replaced by PBS, which was subsequently used for proteomic, ELISA and immunoprecipitation analyses of secreted chemokines and cytokines. A Boyden chamber assay was used to observe human MSC migration towards native and chemokine depleted media. Gene expression levels of chemokine receptors in human MSCs were analysed, and CCL5 was localised in bovine and human IVD by immunohistochemistry. Proteomic analysis revealed the presence of CCL5 and CXCL6 within conditioned media. Higher concentrations of CCL5 were found in the degenerative media, and a relationship was found between interleukin-1 $\beta$ and CCL5 concentration. Chemokine immunoprecipitation showed that MSCs had a significantly reduced chemotactic migration towards CCL5-immunoprecipitated and CCL5/CXCL6 coimmunoprecipitated media, whilst CXCL6 depletion did not change MSC chemotaxis. MSCs showed a significant increase in mRNA expression of the CCL5 receptors, CCR1 and CCR4, upon culture in degenerative media. Furthermore, CCL5 was identified in bovine and human disc tissue by immunohistochemistry. Hence, CCL5 may be a key chemoattractant that is produced and released by the intervertebral disc cells. Therefore, these factors could be used to enhance stem/progenitor cell mobilisation in regenerative therapies for early stages of disc degeneration.
\end{abstract}

Keywords: Chemoattractant; intervertebral disc; mesenchymal stem cells; CCL5/RANTES; degeneration; migration.

*Address for correspondence:

Sibylle Grad, PhD

AO Research Institute Davos

Clavadelerstrasse 8

CH-7270 Davos, Switzerland

Telephone Number: +41814142480

FAX Number: +41814142288

Email: sibylle.grad@aofoundation.org

\section{Introduction}

Effective treatment of intervertebral disc (IVD) degeneration is an unmet medical need that requires strategies for repair due to its inherent poor repair capacity. In the early stages of degeneration, minimally invasive biological repair strategies could aid in the IVD regeneration, such as injectable scaffolds, biomaterials and cell based therapies (Hiyama et al., 2008; Yang and Li, 2009; Collin et al., 2011; Peroglio et al., 2012). Furthermore, there has been great interest in developing new therapeutic techniques such as the use of growth factors, mesenchymal stem cells (MSCs), or delivery of therapeutic genes via cellular transduction (Serigano et al., 2010; Orozco et al., 2011; Zhang et al., 2011). However, it is still uncertain which type of cell, biologics or gene therapy would induce the greatest sustained effect. Additionally, in the cases of growth factors and/or MSCs, their administration could induce an undesired response such as ossification within the damaged area (Huang et al., 2007; Vadala et al., 2012). A cellular response that could induce a sustained therapeutic effect is stem or progenitor cell homing. Stem or progenitor cell homing generally occurring following injury has been described for different musculoskeletal tissues and has also been demonstrated for induced degenerative disc tissue ex vivo (Lee et al., 2010a; Shinohara et al., 2011; Illien-Junger et al., 2012; Seol et al., 2012).

Homing of stem or progenitor cells may be described as the activation of an endogenous mechanism for tissue regeneration. This process has been documented in vivo, whereby systemic MSC injection resulted in the migration of cells towards the site of injury due to the presence of chemokine/chemoattractant signals (Karp and Leng Teo, 2009; Fong et al., 2011). The process of cell migration is controlled by a group of cell-signalling molecules, including inflammatory cytokines that accelerate degeneration (e.g. tumour necrosis factor-alpha (TNF- $\alpha$ ) and interleukin-1 beta (IL-1 $\beta)$ ) and molecules that enable cell migration/chemotaxis to occur (e.g., stromal cell derived factor-1 (SDF-1) and monocyte chemotactic protein-1 (MCP-1)). This latter sub-group of cell-signalling molecules are known as chemokines. It is believed that the release of inflammatory cytokines during degeneration results in the production of various chemokines. Besides the chemokines, molecules that induce chemotaxis or chemically induced migration also include various growth factors, such as insulin-like growth factor-1 (IGF-1), transforming growth factor- $\beta$ (TGF- $\beta$ ), platelet derived growth factor (PDGF), and fibroblast 
growth factor -2 (FGF-2) (Ponte et al., 2007; Lazennec and Richmond, 2010; Ito, 2011).

Studies observing the chemotactic migration of MSCs using various chemoattractants showed that IGF- 1 , TGF- $\beta$, SDF-1 and FGF-2 induced chemoattraction of MSCs (Fiedler et al., 2002; Fiedler et al., 2004; Ozaki et al., 2007; Ponte et al., 2007; Lee et al., 2010b; Baek et al., 2011). Treatment of MSCs with TNF- $\alpha$ helped increase the responsiveness of MSCs towards both growth factors (PDGF, TGF- $\beta$ and IGF-1) and chemokines (SDF-1, MCP-1, and CCL5/RANTES (Regulated upon Activation, Normal T-cell Expressed, and Secreted)) (Ozaki et al., 2007; Ponte et al., 2007; Baek et al., 2011). The results of TNF- $\alpha$ priming studies indicate that the degenerative state has an influence on cellular migration towards injury sites (Ponte et al., 2007). This may be due to the increased expression and responsiveness of the cell surface receptors that facilitate the chemotactic process. Chemokine receptors can be divided into two groups, the $\mathrm{CXC}$ and $\mathrm{CC}$ receptors. These receptors interact with different chemokines from their respective families, e.g., CXCR4 for CXCL12, which is homologous to SDF-1, and CCR1/3/4/5 for CCL5 (Ben-Baruch et al., 1995; Honczarenko et al., 2006).

Recently, we have shown that bone marrow derived MSCs can migrate into induced degenerative intervertebral discs following organ culture in an ex vivo bioreactor system (Illien-Junger et al., 2012). Data also indicated that MSC migration was related to the presence of chemokines and chemoattractants that are released by the disc cells. However, the factors that specifically induce this process need to be identified in order to understand how homing may occur within the intervertebral disc and to develop strategies that could induce or accelerate this process. Therefore, the aim of this study was to identify the chemoattractant(s) that enable MSC homing into the intervertebral disc. Proteomic, gene expression and functional cell migration techniques were used to examine the factors that are produced by induced degenerative discs and would facilitate migration of MSCs towards the site of damage.

\section{Materials and Methods}

\section{Induction of IVD degeneration using an ex vivo bioreactor system}

Intervertebral discs were excised from 5-8 month old bovine tails obtained from a local abattoir. Briefly, discs were excised with intact distal and proximal end-plates and rinsed in phosphate buffered saline (PBS) containing 1000 units $/ \mathrm{mL}$ penicillin and $1000 \mu \mathrm{g} / \mathrm{mL}$ streptomycin. A jet lavage system (Zimmer, Winterthur, Switzerland) was used to clean the end-plates from debris, and discs were further washed using PBS containing 1000 units/ $\mathrm{mL}$ penicillin and $1000 \mu \mathrm{g} / \mathrm{mL}$ streptomycin. The discs (mean diameter: $11.8 \pm 0.9 \mathrm{~mm}$ ) were cultured within a bioreactor system under simulated physiological or induced degenerative conditions (Illien-Junger et al., 2012). In brief, "simulated physiological" conditions comprised of discs cultured in Dulbecco's modified Eagle Medium (DMEM) containing $4.5 \mathrm{~g} / \mathrm{L}$ glucose $+1 \%$ ITS $+1+0.1 \%$
Primocin (all Sigma-Aldrich, Poole, UK) and loaded at a frequency of $0.2 \mathrm{~Hz}(0.6 \pm 0.2 \mathrm{MPa})$ during seven days (low frequency; LF). "Induced degenerative" discs were initially punched with a 22-gauge needle and then fed DMEM + $4.5 \mathrm{~g} / \mathrm{L}$ glucose $+1 \%$ ITS $+1+0.1 \%$ Primocin. Discs were loaded at a frequency of $10 \mathrm{~Hz}$ under the previously described loading parameters (high frequency; HF). Medium was replenished from the discs on days 1, 3, 5 and 7. Spent media from days 3, 5 and 7 were stored frozen for chemotaxis analysis using a Boyden chamber assay.

In separate experiments, "simulated physiological" discs were cultured as described above, while "induced degenerative" discs were punched with a 22 -gauge needle, fed DMEM + $2 \mathrm{~g} / \mathrm{L}$ glucose $+1 \%$ ITS $+1+0.1 \%$ Primocin, and loaded at a frequency of $10 \mathrm{~Hz}$ under the previously described loading parameters (low glucose and high frequency; HF). Reduced glucose condition has been shown to further increase the degenerative state of the IVD ex vivo (Illien-Junger et al., 2010). Medium was removed on day 4 and replaced with $2.5 \mathrm{~mL} \mathrm{PBS}+4.5 \mathrm{~g} / \mathrm{L}$ glucose for each disc condition with loading parameters remaining the same. PBS was removed after two days and then used for subsequent proteomic, ELISA and chemotaxis analysis.

A summary of the experimental settings, sample types and outcome parameters used for this study is shown in Table 1.

\section{Chemotaxis analysis}

Chemotaxis studies required the use of human bone marrow derived mesenchymal stem cells (MSCs) that were isolated using Ficoll gradient procedure as previously described ( $\mathrm{Li}$ et al., 2009). Bone marrow aspirates from vertebral bone or iliac crest were obtained from the University Hospital Bern after ethical approval and informed consent (KEK 188/10). Second passage cells (P2) were used for all experiments.

Chemotaxis analysis was performed on medium samples recovered from each of the time points described ( $n=6$ media from different animals per time point). The bottom Boyden chamber (Neuroprobe, Gothenburg, Sweden) had media from degenerative disc mixed with media from physiological disc to produce a range of media concentrations (100\% degenerative; $75 \%$ degenerative $+25 \%$ physiological; $25 \%$ degenerative $+75 \%$ physiological; $100 \%$ physiological media) that were arranged in columns in the chamber. A polycarbonate membrane $(25$ x $80 \mathrm{~mm}$ membrane: $8 \mu \mathrm{m}$ pores; Neuroprobe) was applied to this chamber and then a top chamber was placed on to the membrane. Passage 2 MSCs from a 41 year old male donor were suspended in each of the medium concentrations described above and added in rows along the top chamber - each row representing a medium concentration. Each well contained 2 x $10^{4}$ MSCs. The chamber was incubated at $37^{\circ} \mathrm{C}$ for six hours to enable cell migration to occur.

The membrane was cleaned using a wiper blade to remove non-migrated cells, fixed with methanol and then stained using toluidine blue. The membrane was mounted on a glass slide and imaged using a motorised microscope at x5 magnification (Axiovert 200m; Zeiss, Jena, Germany). The cells were interactively marked and blind counted for chemotaxis analysis. 
Table 1. Summary of the experimental settings of bovine IVD culture conditions, types and time points of samples, and corresponding outcome parameters.

\begin{tabular}{|c|c|c|c|}
\hline $\begin{array}{l}\text { Experiment } \\
\text { setting }\end{array}$ & IVD culture conditions & Samples and time points & Outcome parameters \\
\hline \multirow{3}{*}{1} & \multirow{3}{*}{$\begin{array}{l}\text { a) Low frequency - } \\
\text { high glucose for } 7 \text { days } \\
\text { b) High frequency - } \\
\text { high glucose for } 7 \text { days }\end{array}$} & $\begin{array}{c}\text { Conditioned media: } \\
\text { d 3, d 5, d } 7\end{array}$ & MSC chemotaxis \\
\hline & & $\begin{array}{l}\text { Total RNA: } \\
\mathrm{d} 2, \mathrm{~d} 4, \mathrm{~d} 7\end{array}$ & Chemokine gene expression \\
\hline & & $\begin{array}{l}\text { Whole IVD: } \\
\text { d } 7\end{array}$ & Immunohistochemistry \\
\hline 2 & $\begin{array}{l}\text { a) Low frequency - } \\
\text { high glucose for } 4 \text { days } \\
\text { + low frequency - } \\
\text { PBS for } 2 \text { days } \\
\text { b) High frequency - } \\
\text { low glucose for } 4 \text { days } \\
\text { + high frequency - } \\
\text { PBS for } 2 \text { days }\end{array}$ & $\begin{array}{l}\text { Conditioned PBS media: } \\
\text { d } 6\end{array}$ & $\begin{array}{l}\text { - Proteomics } \\
\text { - ELISA } \\
\text { - Chemokine immuno-precipitation } \\
\text { and MSC chemotaxis } \\
\text { - MSC chemokine receptor gene } \\
\text { expression }\end{array}$ \\
\hline
\end{tabular}

\section{Proteomics}

Day 4-6 PBS media samples $(n=4$ media from different animals) were lyophilised in preparation for proteomics. The analysis of these samples was performed by the Proteomics Core Facility and Biomedical Proteomics research group, University of Geneva as described by Dayon et al. (Dayon et al., 2008; Dayon et al., 2011). $\mathrm{TMT}^{\circledR}$ isobaric mass tagging (Thermo Scientific, Rockford, IL, USA) was utilised to identify the peptides belonging to specific proteins. TMT mass tags labelled the intact proteins and then a fractionation process was utilised prior to mass spectroscopy analysis. LC-MS/MS was performed on a linear trap quadrupole (LTQ) Orbitrap Velos (Thermo Electron, San Jose, CA, USA) and peptide analysis was performed for identification of peptide sequences using Scaffold 3.0 (Proteome Software, Portland, OR, USA) as previously described and displayed (Epiney et al., 2012).

\section{Chemokine gene expression}

Whole discs from the day of harvest (day 0) and discs cultured for 2, 4 or 7 days under physiological and degenerative culture conditions were initially placed in RNAlater (Sigma-Aldrich) and stored at $4{ }^{\circ} \mathrm{C}$ prior to use ( $n=4-6$ discs per group from different animals). Nucleus pulposus (NP) and annulus fibrosus (AF) tissues were separated using a $5 \mathrm{~mm}$ punch (Kai Medical, Japan). NP and AF samples were then flash frozen in liquid nitrogen and pulverised using a tissue lyser (Qiagen, West Sussex, UK). RNA was extracted using a modified TRI-spin method with TRI Reagent (Molecular Research Centre, Cincinatti, OH, USA) and a total RNA extraction kit (Machery-Nagel, Duren, Germany). Reverse transcription was performed using SuperScript ${ }^{\circledR}$ VILO $^{\text {TM }}$ cDNA Synthesis Kit (Invitrogen, Carlsbad, CA, USA). The following Gene Expression Assays (all from Applied Biosystems, Foster City, CA, USA) were used to quantify the mRNA expression of the chemokines identified from the proteomics study: CCL5/RANTES (Bt03216832_m1) and CXCL6 (Bt03259300_m1). The expression level of the well characterised chemokine, CXCL12 (Bt03276322_m1) was also measured. The real-time PCR was performed using the Step One Plus Real time PCR system (Applied
Biosystems). Relative quantification of target mRNA was performed using the $\Delta \mathrm{C}_{\mathrm{T}}$ method with $18 \mathrm{~S}$ rRNA used for data normalisation (18S ribosomal RNA (Applied Biosystems Cat. No. 431089E)).

\section{ELISA assay}

The concentrations of specific chemoattractants identified in the proteomic analysis were investigated in the physiological and degenerative conditioned media. PBS medium samples from each condition taken between days 4-6 were utilised for this study ( $n=6-8$ media from different animals). The proteins investigated were bovine CCL5/RANTES and bovine CXCL6, alongside the inflammatory cytokines, IL- $1 \beta$ and TNF- $\alpha$. All ELISAs were obtained from Hoelzel Diagnostika (Cologne, Germany) and performed according to manufacturer's instructions.

\section{Immunoprecipitation of chemoattractants}

PBS conditioned degenerative disc medium was immunoprecipitated against specific chemoattractants that were found following the proteomics study $(n=6$ media from different animals). Antibodies against CCL5/ RANTES and CXCL6 (SRB laboratories, Aachen, Germany) were utilised. Each antibody was added to samples of PBS media at $1 \mu \mathrm{g} / \mathrm{mL}$, including a sample containing both antibodies. The samples were incubated at $4{ }^{\circ} \mathrm{C}$ with continuous shaking for one hour. Following incubation, one re-suspended volume of Protein G PLUSAgarose beads (Santa Cruz Biotechnology, Santa Cruz, CA, USA) was added to each sample and then incubated overnight at $4{ }^{\circ} \mathrm{C}$ with shaking. Conditioned PBS media samples with only beads present were also formulated to determine potential unspecific binding of chemotactic proteins.

A Boyden chamber assay was performed with medium arranged in rows in the bottom chamber representing the immunoprecipitated samples (CXCL6 immunoprecipitated out, CCL5 precipitated out and CXCL6/CCL5 immunoprecipitated out) and the untreated sample. The corresponding physiologically conditioned PBS sample containing MSCs from a 40 year old female 
donor was arranged in the top chamber and incubated and analysed as described above.

\section{MSC chemokine receptor response upon culture in degenerative and physiological media}

Passage 2 MSCs from a 47 year old male donor were seeded at $0.5 \times 10^{5}$ cells per well in a 48 -well plate in DMEM/10 \% FCS and allowed to attach overnight. Medium was replenished from each well, replaced with $200 \mu \mathrm{L}$ PBS conditioned physiological and degenerative media ( $n=6$ media from different animals) and incubated for $12 \mathrm{~h}$. RNA was extracted from the cells using TRI reagent, and cDNA synthesis was performed using SuperScript ${ }^{\circledR}$ VILO $^{\text {TM }}$ cDNA Synthesis Kit. Real time PCR analysis was performed as described above. The genes analysed for this investigation were the chemokine receptors CCR1 (Hs00928897_s1), CCR3 (Hs00266213 s1), CCR4 (Hs00747615_s1), CCR5 (Hs99999149_s1) and CXCR1 (Hs01921207_s1) (all Gene Expression Assays from Applied Biosystems).

\section{Immunohistochemistry}

After 7 days of culture under physiological or under degenerative conditions, bovine discs were fixed with formalin, decalcified, embedded in paraffin, and cut sagittally into $6 \mu \mathrm{m}$ sections. Following de-waxing and rehydration, antigen retrieval was performed by treating sections with citrate buffer ( $10 \mathrm{mM}$ sodium citrate, $0.05 \%$ Tween 20, $\mathrm{pH} \mathrm{6.0)} \mathrm{for} 15 \mathrm{~min}$, and then endogenous peroxidases were quenched using $3 \%$ hydrogen peroxide in methanol for $30 \mathrm{~min}$. Sections were blocked with goat serum (1:200, Vector Laboratories) for $1 \mathrm{~h}$ at room temperature and then incubated overnight at $4{ }^{\circ} \mathrm{C}$ with rabbit polyclonal anti-CCL5/RANTES antibody (1:200, Bioss cat.nr. bs-1324R, Woburn, MA, USA) plus goat serum (1:200). For the negative control, the primary antibody was replaced by PBS. Following wash steps, sections were incubated with biotinylated anti-rabbit antibody (1:200) for $30 \mathrm{~min}$, and binding was detected using diaminobenzidine (DAB) detection system (all products by Vector laboratories). The sections were visualised under transmitted light using an upright optical microscope (Axioplan 2, Zeiss). Images were obtained using a 20x objective with a constant acquisition time for all sections (200 ms).

Surgical samples were obtained after informed consent from seven patients who required anterior fusion surgery due to trauma or degeneration (Inselspital, University of Bern, Switzerland). Pre-operative computer tomograms (CT scans) allowed for a modified composite radiographic score for disc degeneration (Benneker et al., 2005). Four samples (average age $25.5 \pm 3.0$ years) were graded 1/5$2 / 5$; three samples (average age $38.7 \pm 4.7$ years) were graded $3 / 5-4 / 5$. Samples were formalin fixed, embedded in paraffin and cut into $6 \mu \mathrm{m}$ thin sections in the transverse plane. Sections were processed and visualised as described above for the bovine samples, using rabbit polyclonal anti-CCL5/RANTES antibody $(2 \mu \mathrm{g} / \mathrm{mL}$, Abcam cat.nr. ab9679, Cambridge, UK) for immunolabelling.

\section{Statistical analysis}

SPSS 19 software was used for statistical analysis (SPSS, Chicago, IL, USA). Non parametric analysis was used for non-symmetrically distributed data sets. Gene expression values of bovine NP and AF cells were normalised to the day $0 \mathrm{NP}$ and $\mathrm{AF}$ values and $\log 10$ transformed. Expression differences between groups (NP-LF, NP-HF, AF-LF, AFHF) were then analysed using the Kruskal-Wallis test and pairwise comparisons after exclusion of outliers for each time point. Expression differences between cells from cultured discs and the day $0 \mathrm{NP}$ and AF values, respectively, were analysed using Mann-Whitney-U test (Fig. 2). Univariate analysis of variance (ANOVA) and GamesHowell post-hoc test was used to analyse differences in cell migration towards different medium concentrations (Fig. 1) and towards differently treated media (Fig. 4a). Differences in chemokine and cytokine concentrations between degenerative and physiological media (Figs. 3a-d) and gene expression differences between MSCs cultured in degenerative and physiological medium (Fig. 4b) were analysed using $t$-tests. Trends between cytokines and chemokines were analysed using Spearman's correlation co-efficient. A $p \leq 0.05$ was observed to have significant differences, and a statistical trend was defined as $p<0.1$.

\section{Results}

\section{Chemoattractants are released from bovine IVDs during organ culture}

Chemotactic analysis of media samples from degenerative discs demonstrated that chemoattractants were released from the tissue at each time point investigated. MSCs were attracted towards increasing concentrations of degenerative media collected at days 3, 5 and 7. There was no significant difference in MSC migration towards $100 \%$ degenerative medium between each time point measured. However, at each time point, there was found to be a significant difference between the media concentrations, specifically with respect to migration from $100 \%$ physiological medium in the upper chamber (Fig. $1 ; p<0.05$ ).

\section{Proteomics shows the presence of chemoattractants in conditioned medium}

Proteomic analysis of the degenerative and physiological media samples identified the presence of 104 proteins in either physiological or degenerative media (Table 2). The proteomic analysis demonstrated the presence of two chemoattractants, CCL5 (RANTES) and CXCL6 (GCP-2), in both physiological and degenerative medium samples. Further analyses focussed on the role of CCL5 and CXCL6 on the migration of MSCs.

\section{Chemokine gene expression is differently regulated in cultured IVD}

mRNA expression levels of the two identified chemokines, CCL5 and CXCL6 were determined in addition to the well-established chemokine, CXCL12. In relation to day 0 mRNA expression, CCL5 mRNA demonstrated a significant increase in expression for NP under 
Table 2. List of proteins found in physiological (LF) and degenerative (HF) media following proteomic analysis. The relative intensity ratio between LF/HF is shown. Significant differences in relative intensity are signified by $*(p<0.05$; $n=4$ independent media samples).

\begin{tabular}{|c|c|}
\hline Protein & $\begin{array}{c}\text { Relative } \\
\text { intensity ratio } \\
\text { between } \\
\text { media }(\mathrm{LF} / \mathrm{HF}) \\
\end{array}$ \\
\hline Alpha-2-macroglobulin & 0.94 \\
\hline Aggrecan core protein & 0.92 \\
\hline Actin, cytoplasmic & 1.14 \\
\hline Alpha actinin-4 & 1.12 \\
\hline Alpha-2-HS-glycoprotein & 1.17 \\
\hline Serum albumin & 0.98 \\
\hline Protein AMBP & 1.24 \\
\hline Angioprotein-related protein 7 & 1.58 \\
\hline Annexin A1 & 0.96 \\
\hline Annexin A2 & 0.9 \\
\hline Annexin A5 & 0.87 \\
\hline Beta-2-glycoprotein-1 & 1.25 \\
\hline Biglycan & 0.95 \\
\hline Complement C3 & 1.03 \\
\hline Complement C4 & 0.97 \\
\hline Calmodulin & $1.86^{*}$ \\
\hline C-C motif chemokine 5 & 0.96 \\
\hline CD44 antigen & 1.63 \\
\hline Complement factor B & 1.37 \\
\hline Complement factor $\mathrm{D}$ & 1.50 \\
\hline Complement factor $\mathrm{H}$ & 0.82 \\
\hline Chondroadherin & 1.02 \\
\hline Chitinase-3-like protein-1 & $0.64 *$ \\
\hline C-type lectin domain family-3 member A & 0.71 \\
\hline Tetranectin & 1.4 \\
\hline Clusterin & $0.59^{*}$ \\
\hline Collagen alpha-1(I) chain & 1.08 \\
\hline Collagen alpha-2 (I) chain & 1.09 \\
\hline Collagen alpha-1(II) chain & 1.05 \\
\hline Cartilage Oligomeric Matrix Protein & 0.9 \\
\hline Cystatin-C & 1.10 \\
\hline Cystatin-B & $2.20^{*}$ \\
\hline C-X-C motif chemokine- 6 & 0.79 \\
\hline Acyl-CoA-binding protein & $2.04 *$ \\
\hline Decorin & 0.93 \\
\hline Dermatopontin & 0.92 \\
\hline Alpha enolase & 1.00 \\
\hline Ezrin & $1.72 *$ \\
\hline Fibrillin-1 & 0.69 \\
\hline Fibrinogen alpha chain & 0.88 \\
\hline Fibromodulin & 1.10 \\
\hline Fibronectin & 0.86 \\
\hline Follistatin-related protein-1 & 0.76 \\
\hline Gelsolin & 1.31 \\
\hline Hyaluronan and proteoglycan link protein & 1.00 \\
\hline Haemoglobin subunit alpha & 1.12 \\
\hline Haemoglobin subunit beta & 0.98 \\
\hline High mobility group protein $\mathrm{B} 1$ & 1.56 \\
\hline Haemopexin & 1.81 \\
\hline Insulin-like growth factor-binding protein-4 & 1.00 \\
\hline
\end{tabular}

\begin{tabular}{|c|c|}
\hline Insulin-like growth factor-binding protein-5 & 0.96 \\
\hline Insulin-like growth factor-binding protein- 6 & 1.28 \\
\hline Interleukin-6 & $0.5^{*}$ \\
\hline Insulin & 1.19 \\
\hline Inter alpha-trypsin inhibitor heavy chain $\mathrm{H} 1$ & 0.93 \\
\hline Keratin type I, cytoskeletal 10 & 1.26 \\
\hline Keratin type II, cytoskeletal 7 & 1.25 \\
\hline Keratin, type II, cytoskeletal 79 & 3.92 \\
\hline Galectin-1 & $2.04 *$ \\
\hline Protein-lysine 6-oxidase & 0.91 \\
\hline Lumican & 1.06 \\
\hline Microtubule-associated protein-4 & $1.88^{*}$ \\
\hline $72 \mathrm{kDa}$ type IV collagenase & $0.61 *$ \\
\hline Moesin & 1.01 \\
\hline Myosin light chain $1 / 3$, skeletal muscle isoform & 1.51 \\
\hline Myocilin & 1.28 \\
\hline Mimecan & 0.63 \\
\hline Alpha-1-acid glycoprotein & 1.14 \\
\hline Pancreactic trypsin inhibitor & 1.34 \\
\hline Protein disulphide isomerase & 1.06 \\
\hline Metallothionein-1 & $1.6^{*}$ \\
\hline Regakine-1 & 1.37 \\
\hline Phosphatidylethanolamine-binding protein-1 & $1.83^{*}$ \\
\hline Phosphoglycerate mutase-1 & 1.30 \\
\hline Peptidoglycan recognition protein-1 & 1.01 \\
\hline Peptidyl-polyl-cis-trans isomerase B & 1.15 \\
\hline Peroxiredoxin-2 & 1.30 \\
\hline Retinol-binding protein-4 & 1.07 \\
\hline Reticulocalbin-3 & 1.2 \\
\hline Ribonuclease-4 & 1.22 \\
\hline Protein S100-A4 & 1.57 \\
\hline Serpin A3-2 & 1.18 \\
\hline Serpin A3-4 & 1.03 \\
\hline Antithrombin-III & 1.27 \\
\hline Pigment epithelium-derived factor & 1.32 \\
\hline Superoxide Dismutase & 2.07 \\
\hline Osteopontin & 1.21 \\
\hline Transgelin & $2.91 *$ \\
\hline Serotransferrin & 1.12 \\
\hline Thrombospondin-1 & 1.07 \\
\hline Thrombospondin-4 & 1.2 \\
\hline Metalloproteinase inhibitor-1 & 0.71 \\
\hline Metalloproteinase inhibitor-2 & 0.89 \\
\hline Thymosin beta-4 & $2.13 *$ \\
\hline Triosephoasphate isomerase & 1.2 \\
\hline Tropomyosin beta chain & 1.49 \\
\hline Tropomyosin alpha-3 chain & 1.16 \\
\hline Transthyretin & 1.01 \\
\hline Thioredoxin & $2.06^{*}$ \\
\hline Polyubiquitin-B & $2.90^{*}$ \\
\hline Versican core protein & 0.9 \\
\hline Vimentin & 1.23 \\
\hline
\end{tabular}

degenerative conditions on day 2, whilst for AF tissue there was a significant increase in expression on day 2 and 4 under both treatments (Fig. $2 \mathrm{a}, p<0.05$ ). In terms of CXCL6 mRNA expression, there was a significant increase in expression within both tissues at each time point, except for AF LF at day 7 (Fig. 2b, $p<0.05$ ). There was a decrease

in CXCL12 mRNA expression within the NP LF and the $\mathrm{AF}$ at day 2, and the AF LF remained down-regulated on day 4 and 7 relative to day 0 (Fig. 2 c, $p<0.05$ ). Finally, both the CCL5 and the CXCL6 mRNA expression were increased $(p<0.05)$ in the AF compared to the NP under LF conditions at day 4. 
Fig. 1. Boyden chamber assessment of human MSC chemotactic migration from raising concentrations of physiological medium in the upper chamber towards $100 \%$ degenerative media in the lower chamber. Basal migration is represented by the dotted line and shows cell migration with $100 \%$ degenerative media in both upper and lower chambers. LF represents physiological low frequency conditions; HF represents degenerative high frequency conditions. Both LF and HF media were collected on day 5 of IVD culture. Data represent mean \pm SEM; $n=6$ media from different animals; ${ }^{a}$ $p<0.05 v s .100 \%$ LF in upper chamber.

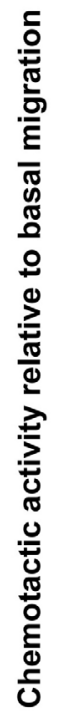

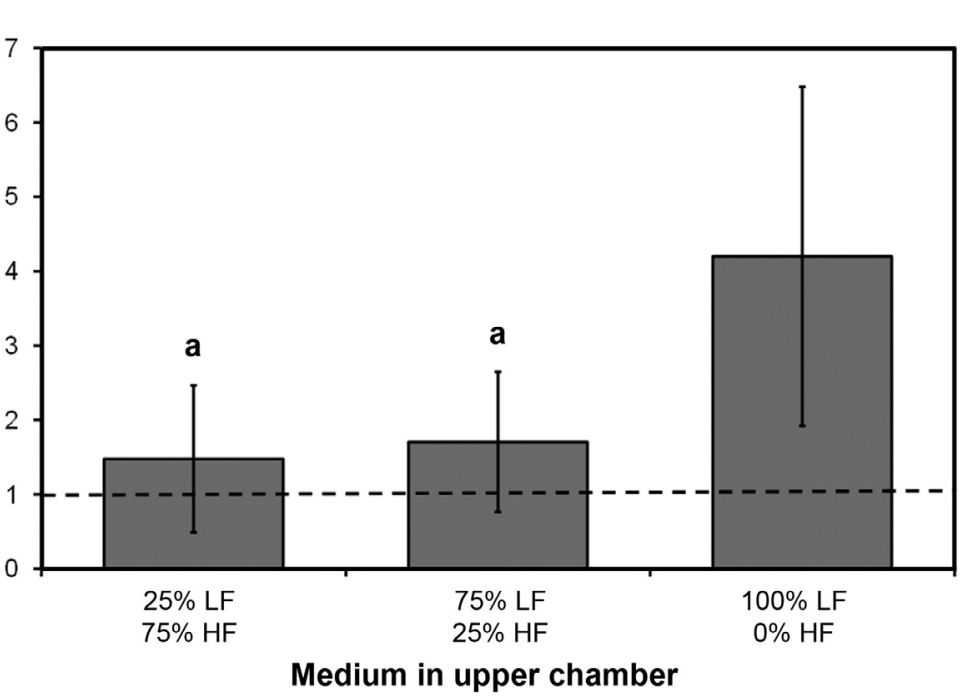

Fig. 2. Relative mRNA expression of the chemoattractants (a) CCL5, (b) CXCL6 and (c) CXCL12 for the discs treated under physiological (NP LF (nucleus pulposus low frequency); $\mathrm{AF}$ LF (annulus fibrosus low frequency)) and degenerative (NP HF (nucleus pulposus high frequency); AF HF (annulus fibrosus high frequency)) conditions. Data represent median $\pm \mathrm{IQR}, n=4-6$ discs from different animals; ${ }^{a} p<0.05 v s$. NP or AF day $0 ;{ }^{\mathrm{b}} p<0.05 v s$. NP LF at day 4 .
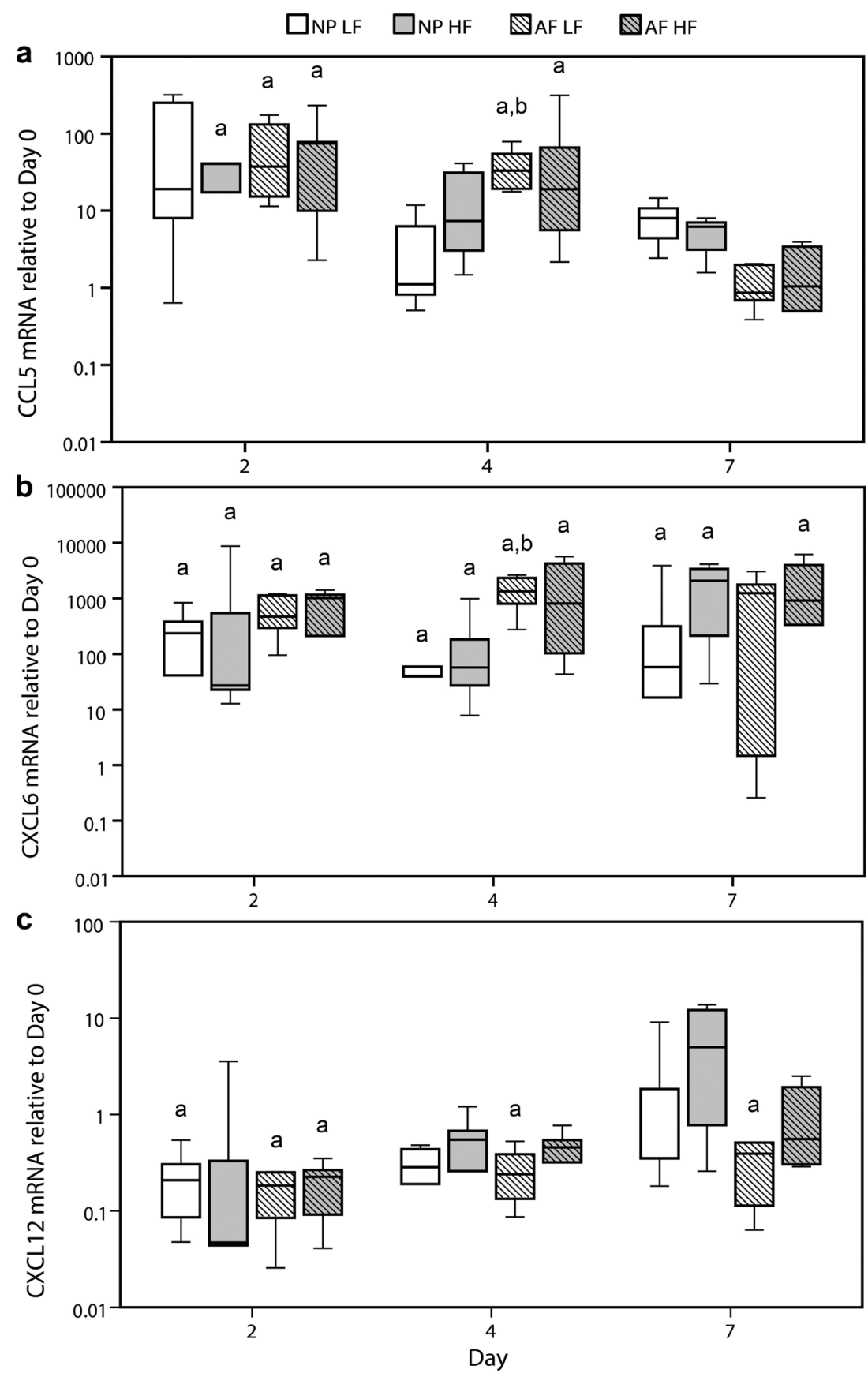

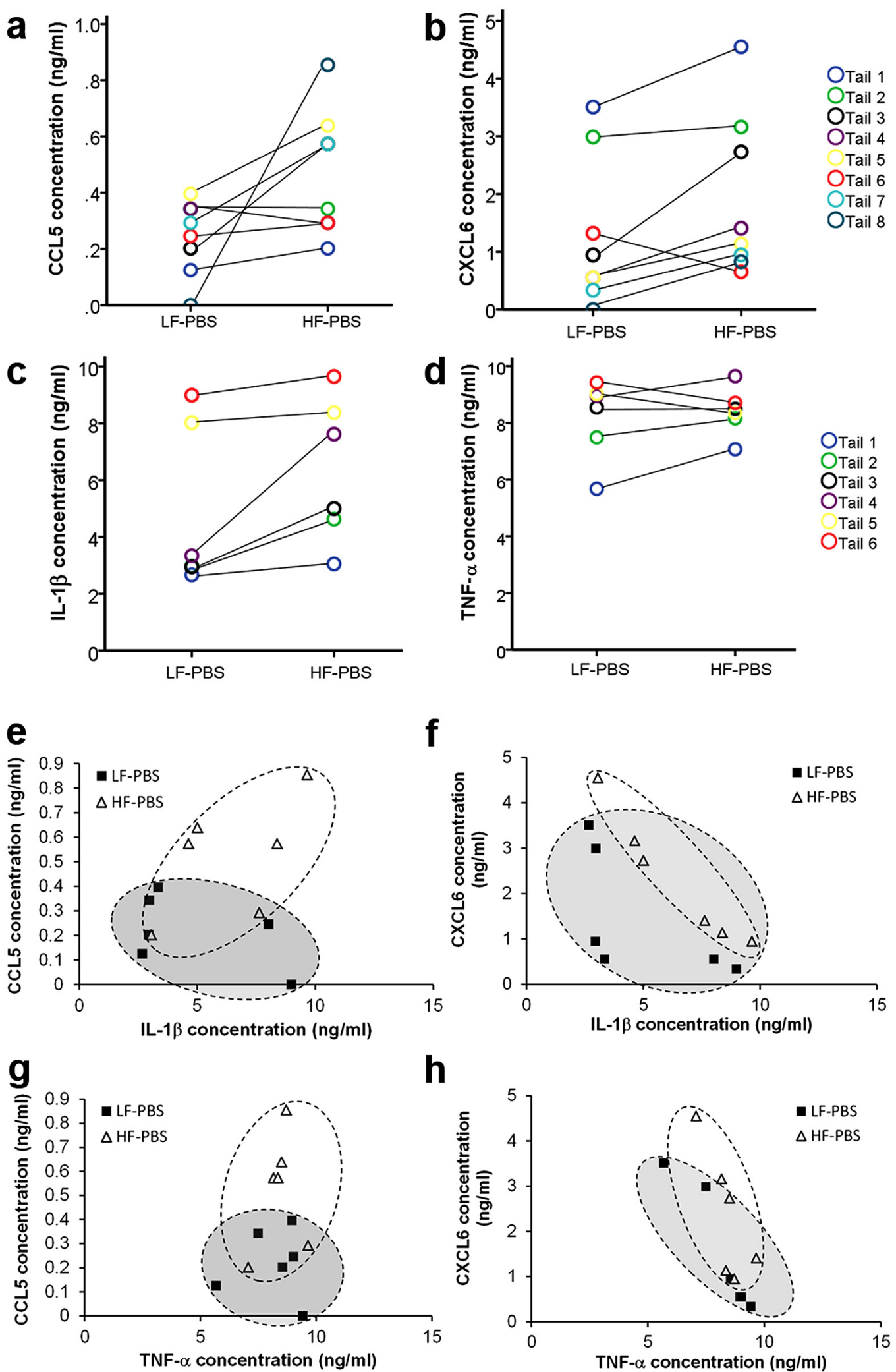

Fig. 3. Chemokine concentrations in individual physiological (LF-PBS) and corresponding degenerative (HF-PBS) media samples for the chemokines, (a) CCL5, (b) CXCL6 $(n=8)$ and the cytokines (c) IL-1 $\beta$ and (d) TNF- $\alpha(n=6)$. Mean \pm S.E.M.: (a) CCL5 LF: $0.24 \pm 0.046 \mathrm{ng} / \mathrm{mL}$, HF: $0.47 \pm 0.079 \mathrm{ng} / \mathrm{mL}(p=0.026)$; (b) CXCL6 LF: $1.28 \pm 0.45 \mathrm{ng} / \mathrm{mL}$, HF: $1.93 \pm 0.050 \mathrm{ng} / \mathrm{mL}$; (c) IL-1 $\beta$ LF: $4.82 \pm 1.17 \mathrm{ng} / \mathrm{mL}$, HF: $6.39 \pm 1.04 \mathrm{ng} / \mathrm{mL}$; (d) TNF- $\alpha$ LF: $8.18 \pm 0.57 \mathrm{ng} / \mathrm{mL}$, HF: $8.41 \pm 0.34 \mathrm{ng} / \mathrm{mL}$. A trend towards higher concentrations in the degenerative media was observed. A relationship towards higher CCL5 in the presence of increased IL-1 $\beta$ concentration under degenerative conditions is shown (LF $r=-0.03$, HF $r=0.64(p=0.17))(\mathbf{e})$, whilst a negative correlation can be described between CXCL6 and IL-1 $\beta$ (LF $r=-0.93(p=0.008), \mathrm{HF} r=-1.0(p<0.001))(\mathbf{f})$. No discernible relationship was observed between TNF- $\alpha$ concentration and CCL5 (LF $r=-0.14$, HF $r=0.41)(\mathbf{g})$, while there was a negative trend between TNF- $\alpha$ and CXCL6 (LF $r=-0.99$ $(p<0.001)$, HF $r=-0.71(p=0.11))(\mathbf{h})$. 
Fig. 4. (a) Boyden chamber assessment of chemotactic activity of immunoprecipitated degenerative conditioned PBS samples towards human MSCs (data represents mean \pm S.E.M $; n=6$ PBS media from different animals; ${ }^{a} p \leq 0.05$ vs. beads only treatment; ${ }^{\mathrm{b}} p<0.05 v s$. no precipitation). Data indicate that CCL5 is a chemoattractant driving the MSC migration. (b) mRNA expression of chemokine receptors for CCL5 and CXCL6 in MSCs that underwent $12 \mathrm{~h}$ incubation in PBS conditioned physiological (LF-PBS) or degenerative (HF-PBS) media (data represents mean \pm S.E.M; $n=4-6$ PBS media from different animals; ${ }^{a} p<0.05 v s$. LFPBS). CCL5 receptors, CCR1 and CCR4, had a significant increase in mRNA expression under degenerative media conditions, whilst no such increase was observed for CXCL6 receptor, CXCR1, compared to MSCs cultured under physiological media conditions. a
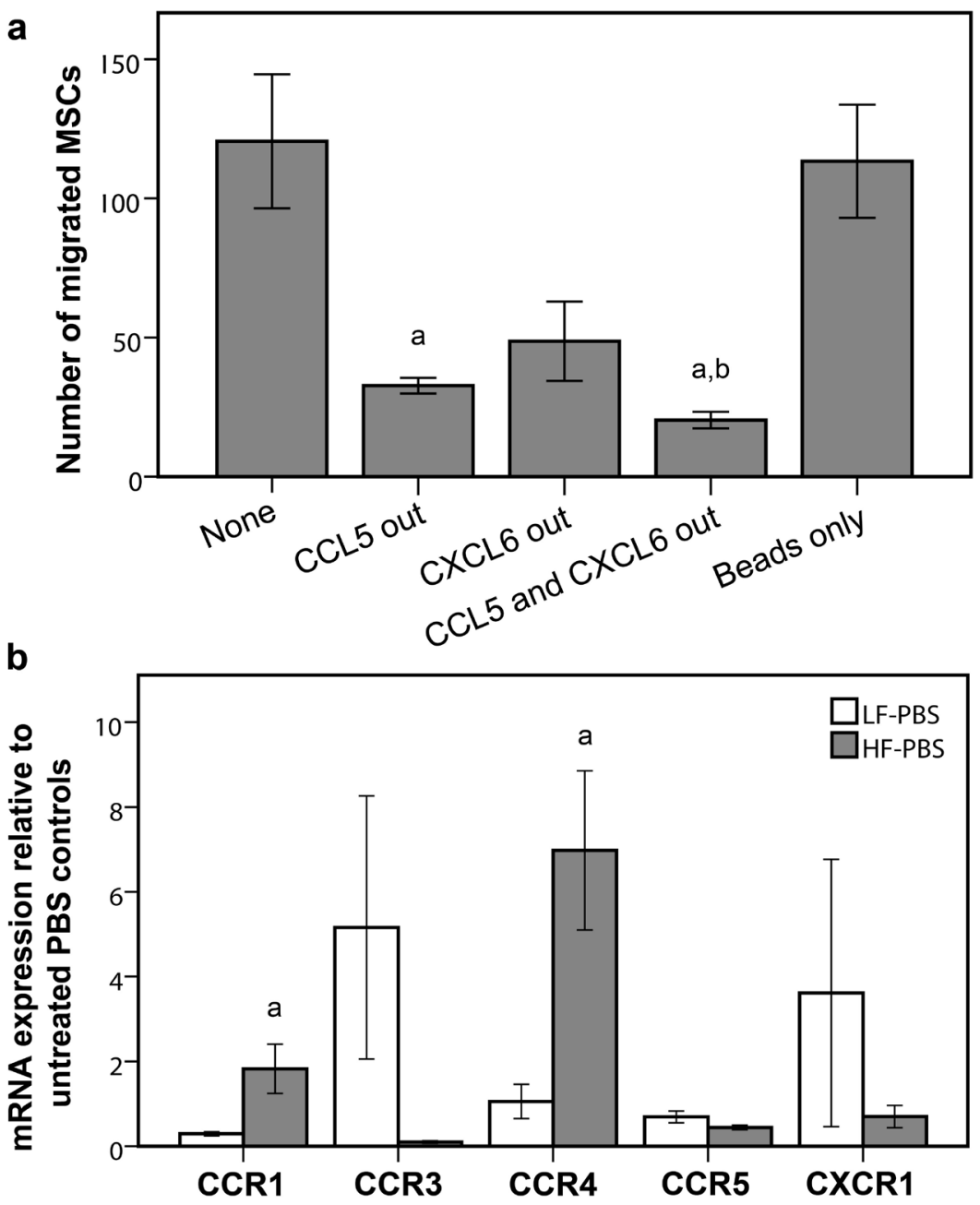

Chemokines (CCL5 and CXCL6) and inflammatory cytokine (IL-1ß) are differentially released by physiological and degenerative discs

It was found that there was a higher CCL5 and CXCL6 concentration in the degenerative compared to the physiological PBS media, whereby the increase in CCL5 concentration in the degenerative medium was significant (LF $0.24 \pm 0.046 \mathrm{ng} / \mathrm{mL}$, HF $0.47 \pm 0.079 \mathrm{ng} / \mathrm{mL}$; mean \pm SEM, $n=8, p=0.026$ ). Figs. $3 \mathrm{a}$ and $3 \mathrm{~b}$ show the differences in the respective concentrations of CCL5 and CXCL6 within the physiological and corresponding degenerative media from discs of each single donor animal. The general trend described by the lines indicates an increase in chemokine concentration within degenerative media samples. IL- $1 \beta$ concentration was found to be higher in degenerative media, although there were no significant differences between conditions (Fig. 3c). TNF- $\alpha$ showed no such trend, and there was no difference between the physiological and degenerative media (Fig. 3d). Furthermore, correlation analysis of IL- $1 \beta$ and the present chemokines demonstrates a positive trend between IL-1 $\beta$ and CCL5 concentrations under degenerative conditions (LF $r=-0.03$, HF $r=0.64(p=0.17)$; Fig. 3e), whilst CXCL6 showed a significant negative correlation with respect the IL-1 $\beta$ under both conditions (LF $r=-0.93$ $(p=0.008)$, HF $r=-1.0(p<0.001)$; Fig. 3f $)$. No clear trend was observed between TNF- $\alpha$ and CCL5 (LF $r=-0.14$, HF $r=0.41$; Fig. $3 \mathrm{~g}$ ), but a negative trend was observed between TNF- $\alpha$ and CXCL6 (LF $r=-0.99(p<0.001)$, HF $r=-0.71(p=0.11)$; Fig. 3h).

\section{CCL5 depletion decreases chemotactic activity of IVD conditioned media}

Immunoprecipitation of either CCL5 or CXCL6 from the degenerative conditioned PBS media reduced their MSC chemo-attractive activity. When both CXCL6 and CCL5 were immunoprecipitated out of the medium, a significant decrease was observed compared to the controls, consisting of no immunoprecipitation and beads only treatment (Fig. $4 \mathrm{a} ; p<0.05$ ). Depletion of only CCL5 resulted in a significant decrease in chemotactic activity compared to the beads only control $(p=0.05)$ and a trend for reduced chemotactic activity compared to the original medium control $(p=0.07)$. There was found to be no significant difference between CXCL6 immunoprecipitated and the control samples, thereby indicating that CCL5 may be the main chemoattractant for MSC homing in the disc. Nevertheless, lowest cell migration was detected after coprecipitation of CXCL6/CCL5 ( $p=0.08$ vs. CCL5 only precipitation), which suggests additive effects of the two chemoattractants. 
Fig. 5. CCL5 immunolabelling of bovine intervertebral disc sections. (a) AF and (b) NP regions of discs cultured under degenerative (HF) conditions; (c) AF and (d) NP regions of discs cultured under physiological (LF) conditions. Black arrows indicate CCL5 positive cells; white arrows indicate CCL5 negative cells. Scale bar $=20 \mu \mathrm{m}$.

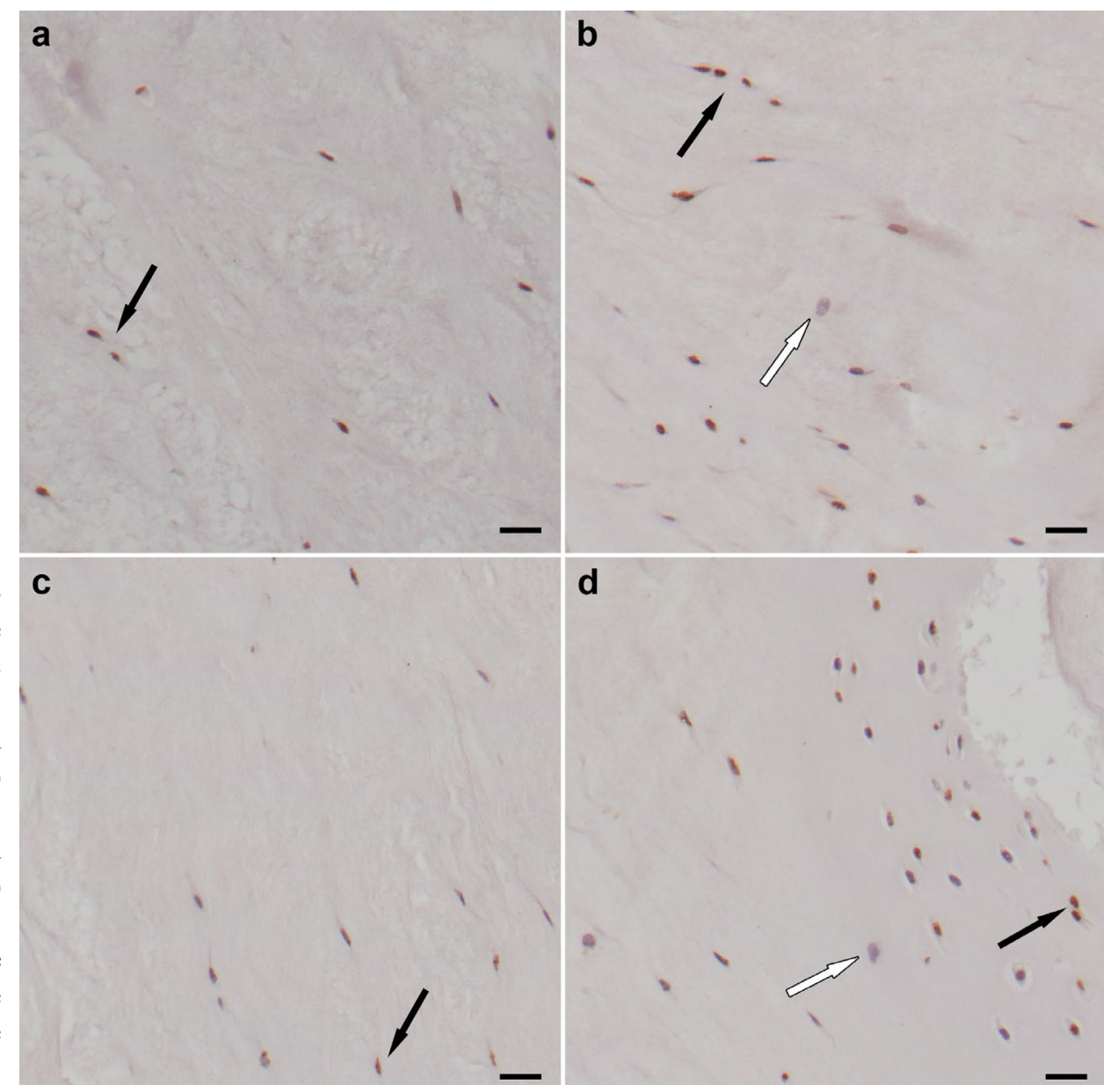

Fig. 6. CCL5 immunolabelling of human intervertebral disc

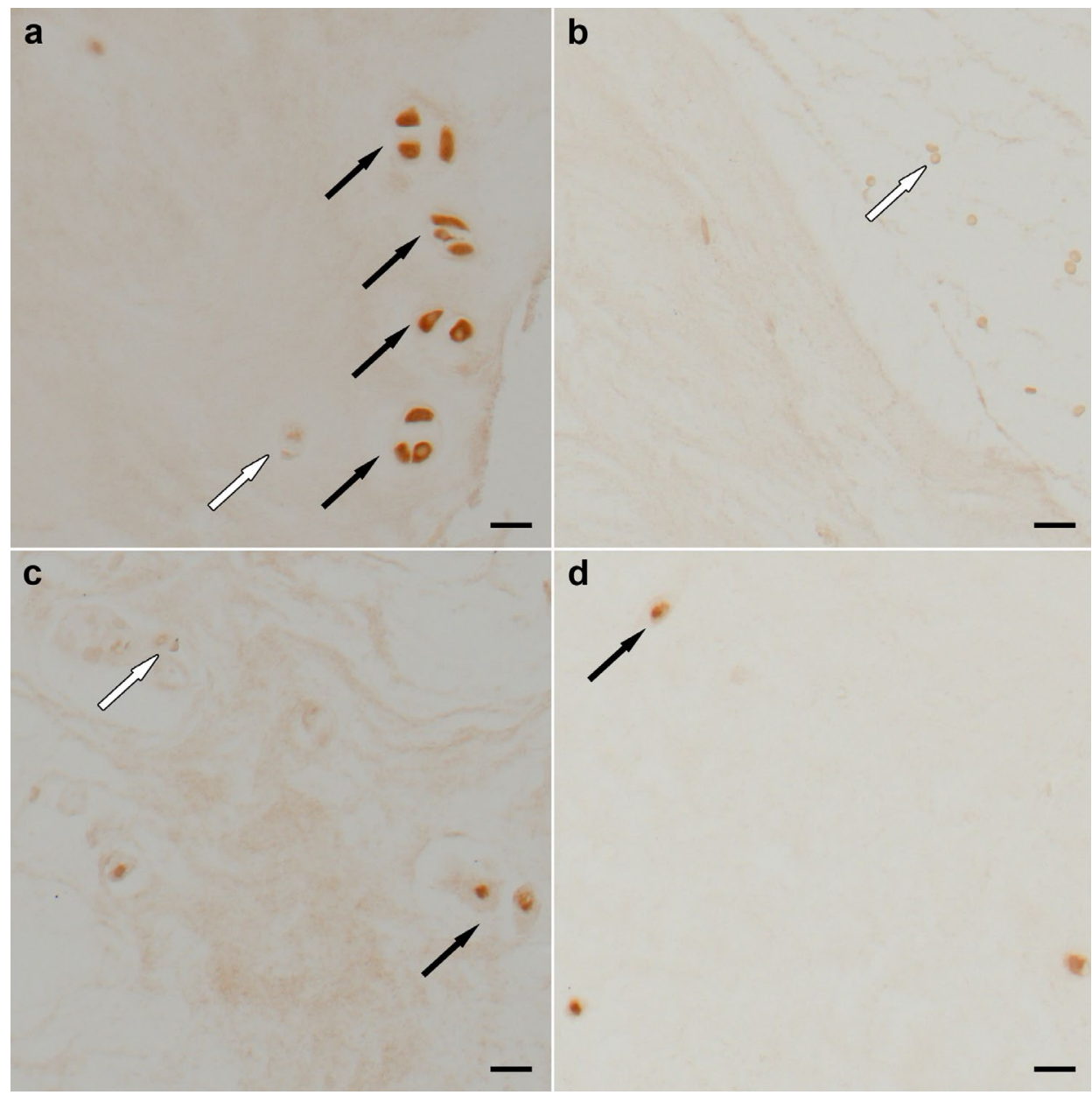
sections. (a) Cluster of cells intensely stained for CCL5 in a degenerative human disc. (b) Negative control of section shown in (a). Single CCL5 positive cells in (c) AF and (d) NP areas of a non-degenerative human disc. Black arrows indicate CCL5 positive cells; white arrows indicate CCL5 negative cells. Scale bar $=20 \mu \mathrm{m}$. 
IVD conditioned medium up-regulates CCL5 chemokine receptor gene expression in MSCs

After $12 \mathrm{~h}$ incubation of MSCs with degenerative conditioned PBS medium, mRNA expression levels of specific chemokine receptors CCR 1 and CCR4, that are known to bind CCL5, were significantly increased compared to their expression in MSCs incubated with physiological conditioned PBS medium (Fig. 4b; ${ }^{*} p<0.05$ ); whilst there was no significant difference between PBS medium treatments for the CXCL6 receptor CXCR1.

\section{CCL5 is present in bovine and human disc tissue}

Cells positive for CCL5 were observed in AF and NP tissues of bovine discs. In both AF and NP tissues of discs cultured under degenerative conditions, single cells positively stained for CCL5 were found in proximity to CCL5 negative cells (Fig. 5a-b). A similar pattern was also observed in AF and NP tissues of discs cultured under physiological conditions (Fig. 5c-d).

Immunohistochemical analysis of surgical samples from human degenerative discs (grade 3-4) showed clusters of cells intensely stained for CCL5 in the annulus fibrosus (Fig.6a) and single CCL5 positive cells in the nucleus pulposus region (in $3 / 3$ patients). In the non-degenerative disc samples (grade 1-2), few single cells positive for CCL5 were observed in the annulus fibrosus of all sections (Fig. $6 \mathrm{c})$; single positive cells were also detected in the nucleus pulposus area in 2/4 patients (Fig. 6d).

\section{Discussion}

The present study sought to identify the chemoattractant(s) that may activate MSC migration towards induced degenerative IVDs for the purpose of tissue regeneration. Two specific chemoattractants were identified within IVD conditioned media following proteomic analysis: CXCL6 and CCL5. Immunoprecipitation of the chemoattractants from the conditioned degenerative medium demonstrated that CCL5 may have a role in MSC recruitment in the disc (Fig. 4a), although there may be an additive effect for both chemoattractants. Furthermore, the increased concentration of CCL5, among other cytokines, in the degenerative media may have enhanced the mRNA expression of CCL5-specific chemokine receptors in the MSCs (Fig. 4b), supporting the hypothesis that CCL5 may be the main MSC chemoattractant in degenerative discs. The positive trend between high IL-1 $\beta$ and CCL5 concentrations within the degenerative conditioned media (Fig. 3e) reinforces the concepts of previous investigations, whereby secretion of cytokines increased the migration potential of MSCs towards chemoattractants. Previous studies have demonstrated CCL5 to be more potent for chemotactic migration of MSCs upon MSC treatment with inflammatory cytokines such as TNF $\alpha$ and IL-1 $\beta$ (Ponte et al., 2007; Baek et al., 2011). CCL5 was originally identified as a product of activated T cells (Schall et al., 1988). It mediates the chemotactic activity of various cell types including monocytes, lymphocytes, dendritic cells, and is involved in wound healing processes (Martins-Green et al., 2013). Apart from its function as a chemokine, CCL5 has also been reported to be involved in inflammatory diseases such as rheumatoid arthritis and atherosclerosis and has recently been identified as a factor to suppress HIV progression (Boiardi et al., 1999; Zernecke et al., 2008; Jones et al., 2011; Secchi et al., 2012).

Studies investigating cellular migration into tissue have identified SDF-1 $\alpha /$ CXCL12 as a model chemoattractant due to its strong chemotactic effect for MSCs, although it remains unknown whether this is a primary chemoattractant in an in vivo or ex vivo system (Ponte et al., 2007; Baek et al., 2011). In fact, our observation that gene expression of CXCL12 demonstrated no up-regulation with respect to day 0 shows that this may not be the primary chemokine that is naturally regulated in the disc (Fig. 2c). In the present investigation, the chemokines CXCL6 and CCL5 were found to be produced by induced degenerative discs (Fig. 3a,b). The difference compared to many previous chemotactic investigations is that the present study was performed using an ex vivo system, whilst others have utilised a trans-well system to understand the migration with exogenous inflammatory cytokines applied to the cells.

In in vitro studies, Baek et al. and Ponte et al. demonstrated that priming MSCs with TNF- $\alpha$ helped to increase their migration towards specific chemokines, CCL5 and CXCL12 (Ponte et al., 2007; Baek et al., 2011). The use of TNF- $\alpha$ may replicate in vivo tissue degeneration, as its production is one of the first steps in this process (Martel-Pelletier et al., 1999; Hoyland et al., 2008; Kapoor et al., 2011). Similarly, the use of our bioreactor system allows for the generation of degenerative discs mimicking in vivo conditions (Illien-Junger et al., 2012). Indeed, we have also found the presence of TNF- $\alpha$ and IL-1 $\beta$ in the conditioned media, indicating an inflammatory response. Sample medium showed an increase in IL- $1 \beta$ concentration by the degenerative discs within our system, whereas there was no marked up-regulation in TNF- $\alpha$ concentration (Fig. 3c,d). This correlates with previous investigations, whereby in human IVDs, it is suggested that IL- $1 \beta$ rather than TNF- $\alpha$ is involved in degeneration mechanisms (Le Maitre et al., 2005; Le Maitre et al., 2007; Hoyland et al., 2008). It should be noted that besides the tendency for increased IL-1 $\beta$ concentration, there appeared to be a positive trend between the concentration of IL$1 \beta$ and CCL5 in the degenerative media samples (Fig. 3e). Furthermore, Kepler et al. recently demonstrated a significant positive correlation in the relationship between IL-1 $\beta$ and CCL5 within human annulus fibrosus tissue from painful discs (Kepler et al., 2013). These findings suggest that production of inflammatory cytokines by the tissue may correspond to an increase in chemokine production, in particular CCL5. The production of inflammatory cytokines may enable chemokine receptors on MSCs to be more responsive to chemokines produced by the tissue and therefore induce greater cell migration, particularly under degenerative conditions. However, it has also been shown that release of cytokines, particularly IL-1 $\beta$, can induce release of specific chemokines from MSCs and therefore may facilitate their homing into the tissue (Carrero et al., 2012). 
Facilitating MSC migration are the specific chemokine receptors that are expressed on the cells. Honczarenko et al. described the presence of a set of functional receptors on MSCs: CCR1, CCR7, CCR9, CXCR4, CXCR5 and CXCR6 were found to be expressed on human bone marrow derived MSCs (Honczarenko et al., 2006). Upon stimulation with CCL5, CCR1 activated specific pathways within the MSCs that enabled the migration process to occur (Honczarenko et al., 2006). In the present investigation, CCR 1 and CCR 4 chemokine receptors associated with the CCL5 chemokine showed an increased mRNA expression in MSCs upon treatment with the degenerative media, and thus the presence of IL-1 $\beta$ and CCL5 in the media may have helped to facilitate MSC migration within our present system (Fig. 4b). Furthermore, the recent study by Kepler et al. using human annulus fibrosus cells suggests that CCR1 may be the primary receptor for CCL5 binding interaction (Kepler et al., 2013).

The present study investigated the specific chemoattractants for MSC recruitment that would enable tissue regeneration in the disc, although a recent investigation has shown that the stimulation of rat nucleus pulposus cells with TNF- $\alpha$ and IL- $1 \beta$ induced the production of another chemokine, macrophage inflammatory protein- 1 alpha (MIP- $1 \alpha /$ CCL 3 ). The chemokine enables the migration of macrophages in the degenerative herniated disc tissue that would help prevent further degeneration, through removal of apoptotic cells by phagocytosis (Wang et al., 2013). This complements the present investigation in that we show a possible MSC-based regeneration pathway, alongside a pathway for preventing further degeneration. Interestingly, CCR1 is also a chemokine receptor for MIP-1 $\alpha /$ CCL3; so the pathways may be inter-linked and CCL5 may also interact with its other receptors, e.g., CCR4. It should be noted that chemokine receptors are binding sites for various chemokines rather than being specific to one chemokine. Nevertheless, what can be ascertained from both studies is that the presence of the inflammatory cytokines and chemokines facilitates the homing process and therefore an inter-link can be established based on the secretion of both sets of factors, whereby secretion of the cytokine increases the responsiveness of MSCs towards the specific chemoattractants, as demonstrated by the MSC priming study using physiological and degenerative conditioned media (Fig. 4b). Furthermore, recent work has shown that CXCL10 is able to recruit human annulus fibrosus cells and thus migration may also occur among native cells within the IVD tissues (Hegewald et al., 2012). Finally, the present investigation shows intense CCL5 expression at the protein level in clusters of cells in human degenerative disc tissue (Fig. 6). This observation basically supports previous findings on CCL5 mRNA expression, which was found to increase with increasing grade of disc degeneration (Kepler et al., 2013).

In the context of disc regeneration, the described cytokines or chemokines may be used within a delivery system, whereby the controlled release of these factors would help facilitate cell homing into the degenerating disc (Goncalves et al., 2012). MSCs may then be recruited from adjacent tissue and migrate to the disc, as has been described in recent in vivo homing studies for both cartilage and bone (Lee et al., 2010a; Mokbel et al., 2011; Seol et al., 2012; Song et al., 2013). This represents an alternative form for regenerating tissues. However, resident nucleus pulposus or annulus fibrosus progenitor cell populations that are present in distinct niches within the disc may also be mobilised to the site of damage and facilitate the regeneration process (Risbud et al., 2007; Sakai et al., 2012). Furthermore, different chemokines may facilitate homing of cells for nucleus pulposus and annulus fibrosus repair, although this requires further investigation.

The model described in the present study has been validated in previous work (Illien-Junger et al., 2010; Illien-Junger et al., 2012). However, certain limitations need to be taken into consideration when comparing it to the situation in human disc degeneration. In particular, our model can simulate a degenerative state on the cellular level, while changes on the extracellular matrix level cannot be clearly observed (Illien-Junger et al., 2010). The reasons for this imply the relatively young age of the animals and the short term culture of the discs.

\section{Conclusions}

Our findings indicate that CCL5 is produced and secreted by the intervertebral disc cells and its release is increased in response to degenerative conditions. Medium from degenerative discs shows a chemotactic effect on human MSCs. Furthermore, this chemotactic effect is strongly reduced by immunoprecipitation of CCL5 and to a lesser extent of CXCL6 from the degenerative medium. These findings suggest that CCL5 may be the main chemoattractant released by degenerating discs. Therefore, these factors could be used to enhance stem/progenitor cell mobilisation in regenerative therapies for early stages of disc degeneration. However, additional studies will be required to confirm the role of these chemokines for cell stimulation in vivo under induced and native degenerative disc conditions.

\section{Acknowledgements}

We would like to acknowledge the funding provided by AOSpine International through SRN Grant 2011_13. We thank Nora Goudsouzian and Sandra Thoeny for their assistance in immunohistochemistry and microscopy.

\section{References}

Baek SJ, Kang SK, Ra JC (2011) In vitro migration capacity of human adipose tissue-derived mesenchymal stem cells reflects their expression of receptors for chemokines and growth factors. Exp Mol Med 43: 596-603.

Ben-Baruch A, Michiel DF, Oppenheim JJ (1995) Signals and receptors involved in recruitment of inflammatory cells. J Biol Chem 270: 11703-11706.

Benneker LM, Heini PF, Anderson SE, Alini M, Ito K (2005) Correlation of radiographic and MRI parameters 
to morphological and biochemical assessment of intervertebral disc degeneration. Eur Spine J 14: 27-35.

Boiardi L, Macchioni P, Meliconi R, Pulsatelli L, Facchini A, Salvarani C (1999) Relationship between serum RANTES levels and radiological progression in rheumatoid arthritis patients treated with methotrexate. Clin Exp Rheumatol 17: 419-425.

Carrero R, Cerrada I, Lledo E, Dopazo J, GarciaGarcia F, Rubio MP, Trigueros C, Dorronsoro A, RuizSauri A, Montero JA, Sepulveda P (2012) ILlbeta induces mesenchymal stem cells migration and leucocyte chemotaxis through NF-kappaB. Stem Cell Rev 8: $905-$ 916.

Collin EC, Grad S, Zeugolis DI, Vinatier CS, Clouet JR, Guicheux JJ, Weiss P, Alini M, Pandit AS (2011) An injectable vehicle for nucleus pulposus cell-based therapy. Biomaterials 32: 2862-2870.

Dayon L, Hainard A, Licker V, Turck N, Kuhn K, Hochstrasser DF, Burkhard PR, Sanchez JC (2008) Relative quantification of proteins in human cerebrospinal fluids by MS/MS using 6-plex isobaric tags. Anal Chem 80: 2921-2931.

Dayon L, Turck N, Garci-Berrocoso T, Walter N, Burkhard PR, Vilalta A, Sahuquillo J, Montaner J, Sanchez JC (2011) Brain extracellular fluid protein changes in acute stroke patients. J Proteome Res 10: 1043-1051.

Epiney M, Ribaux P, Arboit P, Irion O, Cohen M (2012) Comparative analysis of secreted proteins from normal and preeclamptic trophoblastic cells using proteomic approaches. J Proteomics 75: 1771-1777.

Fiedler J, Etzel N, Brenner RE (2004) To go or not to go: Migration of human mesenchymal progenitor cells stimulated by isoforms of PDGF. J Cell Biochem 93: 990998.

Fiedler J, Roderer G, Gunther KP, Brenner RE (2002) BMP-2, BMP-4, and PDGF-bb stimulate chemotactic migration of primary human mesenchymal progenitor cells. J Cell Biochem 87: 305-312.

Fong EL, Chan CK, Goodman SB (2011) Stem cell homing in musculoskeletal injury. Biomaterials 32: 395 409.

Goncalves RM, Antunes JC, Barbosa MA (2012) Mesenchymal stem cell recruitment by stromal derived factor-1-delivery systems based on chitosan/poly(gammaglutamic acid) polyelectrolyte complexes. Eur Cell Mater 23: 249-261.

Hegewald AA, Neumann K, Kalwitz G, Freymann U, Endres M, Schmieder K, Kaps C, Thome C (2012) The chemokines CXCL10 and XCL1 recruit human annulus fibrosus cells. Spine (Phila Pa 1976) 37: 101-107.

Hiyama A, Mochida J, Sakai D (2008) Stem cell applications in intervertebral disc repair. Cell Mol Biol (Noisy-le-grand) 54: 24-32.

Honczarenko M, Le Y, Swierkowski M, Ghiran I, Glodek AM, Silberstein LE (2006) Human bone marrow stromal cells express a distinct set of biologically functional chemokine receptors. Stem Cells 24: 1030-1041.

Hoyland JA, Le MC, Freemont AJ (2008) Investigation of the role of IL-1 and TNF in matrix degradation in the intervertebral disc. Rheumatology (Oxford) 47: 809-814.
Huang KY, Yan JJ, Hsieh CC, Chang MS, Lin RM (2007) The in vivo biological effects of intradiscal recombinant human bone morphogenetic protein-2 on the injured intervertebral disc: an animal experiment. Spine (Phila Pa 1976) 32: 1174-1180.

Illien-Junger S, Gantenbein-Ritter B, Grad S, Lezuo P, Ferguson SJ, Alini M, Ito K (2010) The combined effects of limited nutrition and high-frequency loading on intervertebral discs with endplates. Spine (Phila Pa 1976) 35: 1744-1752.

Illien-Junger S, Pattappa G, Peroglio M, Benneker LM, Stoddart MJ, Sakai D, Mochida J, Grad S, Alini M (2012) Homing of mesenchymal stem cells in induced degenerative intervertebral discs in a whole organ culture system. Spine (Phila Pa 1976) 37: 1865-1873.

Ito H (2011) Chemokines in mesenchymal stem cell therapy for bone repair: a novel concept of recruiting mesenchymal stem cells and the possible cell sources. Mod Rheumatol 21: 113-121.

Jones KL, Maguire JJ, Davenport AP (2011) Chemokine receptor CCR5: from AIDS to atherosclerosis. Br J Pharmacol 162: 1453-1469.

Kapoor M, Martel-Pelletier J, Lajeunesse D, Pelletier JP, Fahmi H (2011) Role of proinflammatory cytokines in the pathophysiology of osteoarthritis. Nat Rev Rheumatol 7: 33-42.

Karp JM, Leng Teo GS (2009) Mesenchymal stem cell homing: the devil is in the details. Cell Stem Cell 4: 206-216.

Kepler CK, Markova DZ, Dibra F, Yadla S, Vaccaro AR, Risbud M, Albert TJ, Anderson DG (2013) The Expression and Relationship of Pro-inflammatory Chemokine RANTES/CCL5 and Cytokine IL-1beta in Painful Human Intervertebral Discs. Spine (Phila Pa 1976).

Lazennec G, Richmond A (2010) Chemokines and chemokine receptors: new insights into cancer-related inflammation. Trends Mol Med 16: 133-144.

Le Maitre CL, Freemont AJ, Hoyland JA (2005) The role of interleukin-1 in the pathogenesis of human intervertebral disc degeneration. Arthritis Res Ther 7: R732-R745.

Le Maitre CL, Hoyland JA, Freemont AJ (2007) Catabolic cytokine expression in degenerate and herniated human intervertebral discs: IL-1beta and TNFalpha expression profile. Arthritis Res Ther 9: R77.

Lee CH, Cook JL, Mendelson A, Moioli EK, Yao H, Mao JJ (2010a) Regeneration of the articular surface of the rabbit synovial joint by cell homing: a proof of concept study. Lancet 376: 440-448.

Lee MJ, Kim J, Kim MY, Bae YS, Ryu SH, Lee TG, Kim JH (2010b) Proteomic analysis of tumor necrosis factor-alpha-induced secretome of human adipose tissuederived mesenchymal stem cells. J Proteome Res 9: 17541762.

Li Z, Kupcsik L, Yao SJ, Alini M, Stoddart MJ (2009) Chondrogenesis of human bone marrow mesenchymal stem cells in fibrin-polyurethane composites. Tissue Eng Part A 15: 1729-1737.

Martel-Pelletier J, Alaaeddine N, Pelletier JP (1999) Cytokines and their role in the pathophysiology of osteoarthritis. Front Biosci 4: D694-D703. 
Martins-Green M, Petreaca M, Wang L (2013) Chemokines and their receptors are key players in the orchestra that regulates wound healing. Advances in Wound Care 2: 327-347.

Mokbel AN, El Tookhy OS, Shamaa AA, Rashed LA, Sabry D, El Sayed AM (2011) Homing and reparative effect of intra-articular injection of autologus mesenchymal stem cells in osteoarthritic animal model. BMC Musculoskelet Disord 12: 259.

Orozco L, Soler R, Morera C, Alberca M, Sanchez A, Garcia-Sancho J (2011) Intervertebral disc repair by autologous mesenchymal bone marrow cells: a pilot study. Transplantation 92: 822-828.

Ozaki Y, Nishimura M, Sekiya K, Suehiro F, Kanawa M, Nikawa H, Hamada T, Kato Y (2007) Comprehensive analysis of chemotactic factors for bone marrow mesenchymal stem cells. Stem Cells Dev 16: 119-129.

Peroglio M, Grad S, Mortisen D, Sprecher CM, Illien-Junger S, Alini M, Eglin D (2012) Injectable thermoreversible hyaluronan-based hydrogels for nucleus pulposus cell encapsulation. Eur Spine J 21 Suppl 6: S839-S849.

Ponte AL, Marais E, Gallay N, Langonne A, Delorme B, Herault O, Charbord P, Domenech J (2007) The in vitro migration capacity of human bone marrow mesenchymal stem cells: comparison of chemokine and growth factor chemotactic activities. Stem Cells 25: 1737-1745.

Risbud MV, Guttapalli A, Tsai TT, Lee JY, Danielson KG, Vaccaro AR, Albert TJ, Gazit Z, Gazit D, Shapiro IM (2007) Evidence for skeletal progenitor cells in the degenerate human intervertebral disc. Spine (Phila $\mathrm{Pa}$ 1976) 32: 2537-2544.

Sakai D, Nakamura Y, Nakai T, Mishima T, Kato S, Grad S, Alini M, Risbud MV, Chan D, Cheah KS, Yamamura K, Masuda K, Okano H, Ando K, Mochida J (2012) Exhaustion of nucleus pulposus progenitor cells with ageing and degeneration of the intervertebral disc. Nat Commun 3: 1264.

Schall TJ, Jongstra J, Dyer BJ, Jorgensen J, Clayberger C, Davis MM, Krensky AM (1988) A human T cell-specific molecule is a member of a new gene family. J Immunol 141: 1018-1025.

Secchi M, Longhi R, Vassena L, Sironi F, Grzesiek S, Lusso P, Vangelista L (2012) Enhancement of antiHIV-1 activity by hot spot evolution of RANTES-derived peptides. Chem Biol 19: 1579-1588.

Seol D, McCabe DJ, Choe H, Zheng H, Yu Y, Jang K, Walter MW, Lehman AD, Ding L, Buckwalter JA, Martin JA (2012) Chondrogenic progenitor cells respond to cartilage injury. Arthritis Rheum 64: 3626-3637.

Serigano K, Sakai D, Hiyama A, Tamura F, Tanaka M, Mochida J (2010) Effect of cell number on mesenchymal stem cell transplantation in a canine disc degeneration model. J Orthop Res 28: 1267-1275.

Shinohara K, Greenfield S, Pan H, Vasanji A, Kumagai K, Midura RJ, Kiedrowski M, Penn MS, Muschler GF
(2011) Stromal cell-derived factor-1 and monocyte chemotactic protein-3 improve recruitment of osteogenic cells into sites of musculoskeletal repair. J Orthop Res 29: 1064-1069.

Song G, Habibovic P, Bao C, Hu J, van Blitterswijk CA, Yuan H, Chen W, Xu HH (2013) The homing of bone marrow MSCs to non-osseous sites for ectopic bone formation induced by osteoinductive calcium phosphate. Biomaterials 34: 2167-2176.

Vadala G, Sowa G, Hubert M, Gilbertson LG, Denaro V, Kang JD (2012) Mesenchymal stem cells injection in degenerated intervertebral disc: cell leakage may induce osteophyte formation. J Tissue Eng Regen Med 6: 348-355.

Wang J, Tian Y, Phillips KL, Chiverton N, Haddock G, Bunning RA, Cross AK, Shapiro IM, Le Maitre CL, Risbud MV (2013) Tumor necrosis factor alpha- and interleukin1beta-dependent induction of CCL 3 expression by nucleus pulposus cells promotes macrophage migration through CCR1. Arthritis Rheum 65: 832-842.

Yang X, Li X (2009) Nucleus pulposus tissue engineering: a brief review. Eur Spine J 18: 1564-1572.

Zernecke A, Shagdarsuren E, Weber C (2008) Chemokines in atherosclerosis: an update. Arterioscler Thromb Vasc Biol 28: 1897-1908.

Zhang Y, Chee A, Thonar EJ, An HS (2011) Intervertebral disk repair by protein, gene, or cell injection: a framework for rehabilitation-focused biologics in the spine. PM R 3: S88-S94.

\section{Discussion with Reviewer}

Nam Vo: Could you speculate a bit further on how chemoattractants such as CCL5 could be adapted into a therapy for painful disc degeneration?

Authors: It is conceivable that early stages of painful disc degeneration with insufficient response to conservative treatment may be addressed by application of chemoattractants. The hypothesis would be that the chemoattractant would accelerate the endogenous repair response by enhancing recruitment of regenerative stem cells. The roles of recruited cells involve their differentiation, as well as anabolic and anti-inflammatory trophic effects. These effects are suggested to reduce pain, since both structural failure and inflammatory processes are known to contribute to painful disc degeneration.

Proof-of-concept studies of induced stem cell recruitment have successfully been performed in cartilage repair, using biomaterial scaffolds loaded with chemokines. For IVD repair, injectable hydrogels may be more attractive for chemoattractant delivery. Moreover, if an annular defect is implied, an appropriate annular closure system will need to be provided to ensure effective repair. Further organ culture and in vivo studies will be necessary to assess the regenerative effects of chemokine delivery in early degenerative discs. 